\title{
Modifications of the ionosphere prior to large earthquakes: report from the lonosphere Precursor Study Group
}

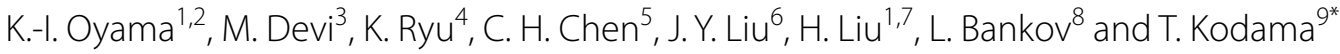

\begin{abstract}
The current status of ionospheric precursor studies associated with large earthquakes (EQ) is summarized in this report. It is a joint endeavor of the "Ionosphere Precursor Study Task Group," which was formed with the support of the Mitsubishi Foundation in 2014-2015. The group promotes the study of ionosphere precursors (IP) to EQs and aims to prepare for a future EQ dedicated satellite constellation, which is essential to obtain the global morphology of IPS and hence demonstrate whether the ionosphere can be used for short-term EQ predictions. Following a review of the recent IP studies, the problems and specific research areas that emerged from the one-year project are described. Planned or launched satellite missions dedicated (or suitable) for EQ studies are also mentioned.
\end{abstract}

\section{Background}

Anomalous behavior before large earthquakes (EQs) has been reported in several geophysical parameters, for example, VLF propagation (Hayakawa et al. 2010), infrared emission (Ouzounov and Freund 2004), and particle precipitation (Aleksandrin et al. 2003; Sgrigna et al. 2006), although the existence of particle precipitation triggered by VLF waves associated with such EQs is controversial. Instances of abnormal animal behavior prior to EQs have also been reported, and an extensive summary of such observations is available in books by Rikitake (2003) and Ikeya (2004).

Among EQ-related precursor phenomena, the effects of large EQs on the ionosphere have also been reported (Depueva and Rotanava 2000; Zakharenkova et al. 2007; Zhao et al. 2008; Jhuang et al. 2010; Devi et al. 2010a, 2013; Ryu et al. 2014a). The main data sources are total electron content (TEC) and F2 peak density (NmF2). The precursor seems to appear as a daytime increase in TEC and/or NmF2 from several days to several hours before the EQ, when it exists.

\footnotetext{
*Correspondence: kodama.tetsuya@jaxa.jp

${ }^{9}$ Japan Aerospace Exploration Agency, Tsukuba, Japan

Full list of author information is available at the end of the article
}

Recently, reports based on satellite data have started to appear (Parrot et al. 2006; Oyama et al. 2008, 2011; Akhoondzadeh et al. 2010; Ryu et al. 2014b). Zakharenkova et al. (2007) studied the Hokkaido EQ which occurred on September 25, $2003(M=8.3)$ using TEC along with individual satellite passes. These reports suggest that the study of the ionosphere as an EQ precursor has some unforeseen potential for applications as well as for basic research (Devi et al. 2010b), although it is opined by some that TEC might not be practical for short-term predictions (Astafyeva and Heki 2011).

However, scientists who have been studying the ionosphere for a long time are still skeptical about the precursor effects (Rishbeth 2007), and only a small fraction of the ionospheric scientists are actively engaged in this subject. This is understandable for several reasons. Data analysis methods to identify the precursors have not yet been established, which means that scientists working on the subject must consume a lot of time and energy for developing such methods. The number of papers produced on this topic is therefore low compared to other research topics. The study of the topic also requires deep knowledge of the ionosphere, which makes it hard for young scientists to tackle. Furthermore, a research proposal with a title such as "Precursor Study of Earthquake Using Ionospheric Parameters" is less likely to be 
supported as reviewers still find it difficult to accept the existence of EQ effects on the ionosphere.

Whatever the reasons are, however, we believe that this issue should be pursued to explore the possibility of EQ prediction as long as the possibility exists. Although the number of papers on the topic has significantly increased in recent years and the quality of the papers appears to have improved, we still do not have enough evidence to warrant our credibility regarding such precursor effects on the ionosphere for the purpose of EQ prediction.

\section{Methods}

Several steps are to be followed to establish a reliable methodology (including features of EQ disturbance) for the short-term prediction of EQs.

The first step is to find common features of precursor disturbances. Features that are listed as ionosphere disturbances in previous studies are described here. In general, large shallow EQs $(M>6$, with depths of less than $30 \mathrm{~km}$ ) seem to show precursor features in the ionosphere that depend on local time and latitude. It seems that EQs that occur deep in the sea do not show clear variations. There are cases in which we cannot detect ionospheric disturbances, such as the Chuetsu EQ that occurred on October 23, 2004 in Japan. The depth of this $E Q$ was about $30 \mathrm{~km}$. The modification effects of the EQs on the ionosphere seem to be diverse.

One piece of information that we need to know is the area of the geographic region affected by the ionospheric disturbance in terms of magnitude of the response. The ground scale is reported by Dobrovolsky et al. (1979) as $R=10^{0.43 \mathrm{M}}$, where $R$ and $M$ are the radius of the EQ preparation zone in kilometers and EQ magnitude on the Richter scale, respectively. According to a few in situ satellite observations, the disturbed region extends across a wide range of latitudes and longitudes (Oyama et al. 2008), such as $60^{\circ}$ in the East-West (EW) direction and $40^{\circ}$ in the North-South (NS) direction for large EQs of $M>6$. The ionosphere disturbance studied with TEC and satellite electron density measurement for the Wenchuan EQ is roughly of the same order as that reported by Dobrovolsky (Ryu et al. 2014c).

The disturbed area is much larger than that reported by Saradjian and Akhoondzadeh (2011). The real disturbed area depends on the accuracy of the satellite data. Even small variations of the electron density can be detected if the satellite measurements have high sensitivity and accuracy.

The second step is to make further efforts to refine event analysis using existing satellite data. The main problems that we encounter include a lack of systematically archived data over a long period of time from satellites as well as ground observations suitable for data analysis. Measurements of TEC and NmF2 are locally limited on land. Japan needs to obtain further data for the ocean, especially in eastern Japan. Systematically archived long-period data over Chile, where EQs occur frequently, are very scarce due to the existence of the Pacific Ocean in the west and a limited number of observation sites in the east.

The NmF2 value shows less obvious modification related to EQs. We can therefore say that, so far, TEC and NmF2 data can be used for scientific studies, but they are not applicable to short-term EQ predictions (Astafyeva and Heki 2011). It is also noted that establishing a morphology of the ionosphere modification from groundbased data is almost impossible, even locally, because of the possibility that no EQ signature is seen over the epicenter. It is further noted that the precursor signal could be mixed with day-to-day variability of the ionosphere. Efforts are needed to filter out non-EQ-related forcing from above and below the ionosphere to identify the precursor signal, which is difficult because the ionosphere changes even under quiet conditions.

The third step is to determine the mechanism of the EQ-related ionosphere disturbance. Reasonable mechanisms of ionosphere disturbance are far more difficult to identify because no systematic morphology of ionosphere modification has been established regarding latitude, longitude, and local time. The probable source seems to be an electric field. There is supporting evidence for this such as atmosphere glow and spontaneous switching off of televisions (Ikeya 2004). Moreover, EQ-related ionosphere disturbances are found at conjugate points as well. Recently, we found from the Defense Meteorological Satellite Program (DMSP) data in the US that mid-latitude trough moves equatorward during EQ preparation times, and density of atomic oxygen ion $\mathrm{O}^{+}$ increases, especially over the geomagnetic equator in the case of the March 11, 2011 Tohoku EQ (Oyama et al. 2015a). Electron density ( $\mathrm{Ne}$ ) data observed by CHAMP also show similar behavior for the EQ which occurred on January 13, 2007, listed in Table 1 (Oyama et al. 2015b). The studies continue.

The fourth necessary step is our final goal, that is, to find a feature that can be used to predict EQs. To reach to this goal and find a common feature that appears before each EQ, more event studies are required.

To accomplish the goals described above, satellite observation is essential, and a group of scientists is needed for a satellite mission. Taking Japan as one example, few scientists are aware of the need for such satellite missions. This situation makes difficulties even in forming a working group for the dedicated satellite mission. Under this situation, the best we can do is to accumulate new findings through which we can 
Table 1 List of the earthquakes aimed for the data analysis (provided by Japan Meteorological Agency)

\begin{tabular}{|c|c|c|c|c|c|c|c|c|c|c|}
\hline Year & Month & Day & Hour & Minutes & Seconds & lat. & lon. & Dep (km) & $M$ & Remarks \\
\hline 2007 & 01 & 13 & 04 & 23 & 21.00 & 46.23 & 154.55 & 10 & 8.1 & High-latitude EQ \\
\hline 2007 & 03 & 25 & 00 & 41 & 57.91 & 37.132 & 136.411 & 40 & 6.9 & USGSD $=30.5$ \\
\hline 2007 & 07 & 16 & 01 & 13 & 22.55 & 37.334 & 138.365 & 41 & 6.8 & \\
\hline 2008 & 05 & 07 & 16 & 45 & 18.77 & 36.136 & 141.364 & 159 & 7.0 & \\
\hline 2008 & 06 & 13 & 23 & 43 & 45.36 & 39.017 & 140.528 & 21 & 7.2 & \\
\hline 2010 & 02 & 26 & 20 & 31 & 25.92 & 25.551 & 128.408 & 104 & 7.2 & \\
\hline
\end{tabular}

persuade other interested people and wait until scientists from other countries who also suffer from EQ disasters are ready to launch satellites dedicated to their investigations (Oyama et al. 2010). For justifying the launch of a satellite dedicated to EQ investigations, we need to undertake the analysis/study of a small number of large EQ events, seeking to identify their precursor effects/signatures in the ionosphere and to propose possible mechanism(s) to explain any observed ionospheric modification. Although we do not have enough satellite data, we should make a maximum effort to study these EQs.

In pursuit of this goal, we organized an "Ionosphere Precursor Study Task Group (IPSTG)" with the support of the Mitsubishi Foundation in October 2014 as a oneyear project. The data to be studied include both groundbased and satellite data.

Under IPSTG, as a first step, we have chosen EQs of $M$ larger than seven that occurred in Japan during 20072010, because data from four satellites are available during this period. The EQs are listed in Table 1. EQ which occurred on January 13, 2007 (Table 1) is intensively studied together with the magnitude 9.0 Tohoku EQ on March 11, 2011 (38.297 N, 142.372 E), especially in relation to mid-latitude trough as we describe in "Results" section.

Data observed by four satellites are used. These satellites are DMSP, CHAMP, DEMETER, and Formosat-3/ COSMIC. The orbital heights are $800 \mathrm{~km}$ (DMSP), $700 \mathrm{~km}$ (DEMETER), and 450-380 km (CHAMP) during July 2001-June 2007. Local time of these three sunsynchronous orbit satellites is morning and evening. The Taiwan constellation satellite Formosat-3/COSMIC can provide a height profile of $\mathrm{Ne}$ through radio occultation over the whole globe for all local times. The satellite data used mainly for the event studies are height profiles of electron density Ne by Formosat-3/COSMIC, Ne from CHAMP and DEMETER, and densities of the atomic oxygen ion from DMSP. Ground data (NmF2 and TEC) are mainly used for statistical analysis to confirm the existence of ionosphere modifications. Six scientists from
Bulgaria, India, Korea, Taiwan, and Japan are working to extract persuasive data for the ionosphere community.

\section{Results}

\section{Statistics on the TEC modification}

During our project period, statistics on the possible ionosphere disturbance before large earthquake were conducted for $157 \mathrm{EQs}$ with $M>6$ that occurred in Japan from January 1998 to February 2015 using both NmF2 and TEC data.

The epicenters of the EQs of $M \geq 6$ are shown in Fig. 1. One of the statistical results is shown in Fig. 2, where days when TEC shows abnormal disturbance (increase or decrease) before earthquakes are counted depending on $M$. We follow statistical analysis method proposed by Liu et al. (2004, 2014a, b). The number of the earthquakes is 157 for the earthquakes of $6.0 \leq M<6.5$, 51 for the earthquakes of $6.5 \leq M<7.0$, and 27 for $M \geq 7$. As Fig. 2 shows, for the EQs of $6.0 \leq M<6.5$, about $38 \%$ of the

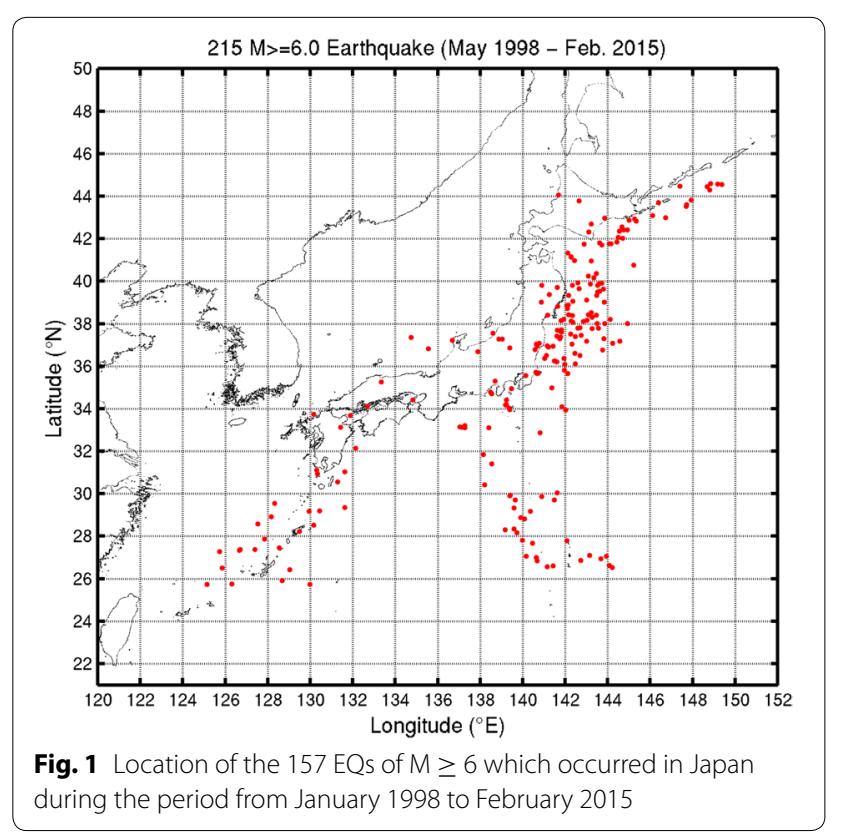




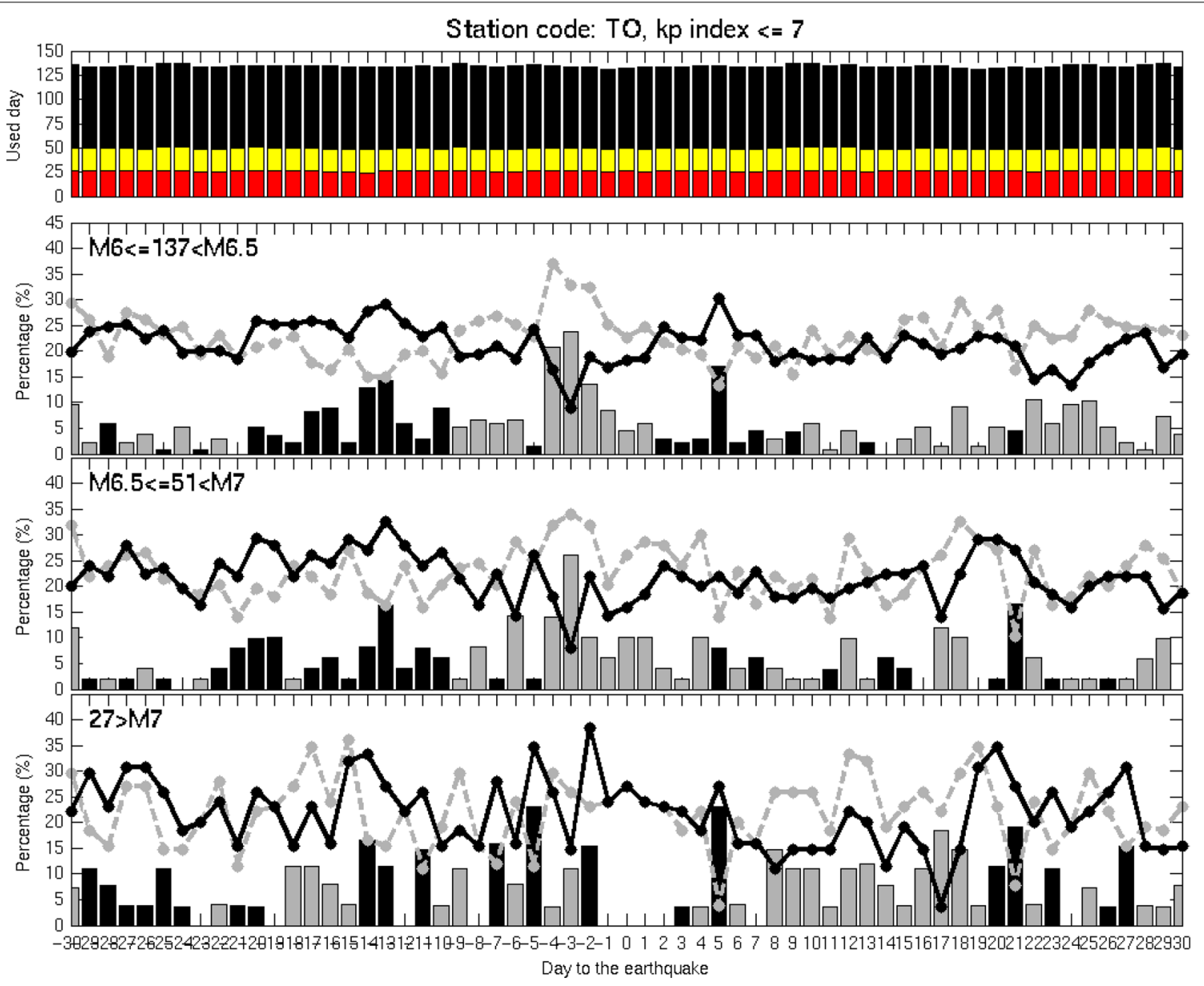

Fig. 2 Occurrence rate of ionosphere disturbance at Kokubunji. Top panel shows the number of the earthquakes of different magnitudes (black bar for EQs of $6.0 \leq M<6.5$, yellow bar for the EQs of $6.5 \leq M<7.0$, and red bar for $M \geq 7$ ). Gray and black lines in the lower three panes indicate the event percentage of positive and negative anomaly, respectively. Gray and black bars indicate difference of the number of the cases for positive and negative deviation, respectively

EQs show the positive disturbance, while $15 \%$ of TEC shows the reduction. The remaining ( $47 \%)$ events do not show any change. The disturbance appears 1-4 days before the EQs. Similar trend is found for the EQs of $6.5 \leq M<7$. For the EQs of $M \geq 7$, the disturbance cannot be identified clearly. One of the possible reasons for this is that near the epicenter, ionosphere disturbance is less obvious than that at other distant places, as DE-2 data show (Oyama et al. 2011). Further studies are needed (1) to conduct similar data analysis by taking into consideration the distance from the epicenter, and (2) to study individual EQ which does not show the disturbance and find the reason.

\section{NmF2 behavior during March 11, $2011 \mathrm{EQ}$}

The EQ which occurred on March 11, 2011 should be studied for its various aspects, although many works have been already reported. We are also studying this EQ using ground-based data NmF2 and TEC in addition to satellite data. Difficult problem regarding the study of this EQ is high geomagnetic disturbance: Kp gradually increases from March 9, reaches the peak value on March 11, and then reduces on March 12. Dst shows the lowest (about $-70 \mathrm{nT}$ ) on March 10. Solar radio flux F10.7 reached a peak on March 9. AU is higher than 200nT during March 9-11. AL shows the value less than $-400 \mathrm{nT}$ during the same period. To distinguish the effect of space weather from possible EQ effect, ionosphere needs to be studied in global scale. If NmF2 or/and TEC shows local anomaly around the epicenter region, we might possibly exclude the space weather effect.

According to this idea, we plotted latitudinal variation of NmF2 which was measured in the longitude of Japan.

Figure 3 shows the variation of NmF2/NmF2 mean at 11 ionosonde stations located nearly at the same longitude of Kokubunji for the period of 1 week before and after the EQ. NmF2 mean is a value which is averaged at each station for 1 month before and after the EQ. It is noted 


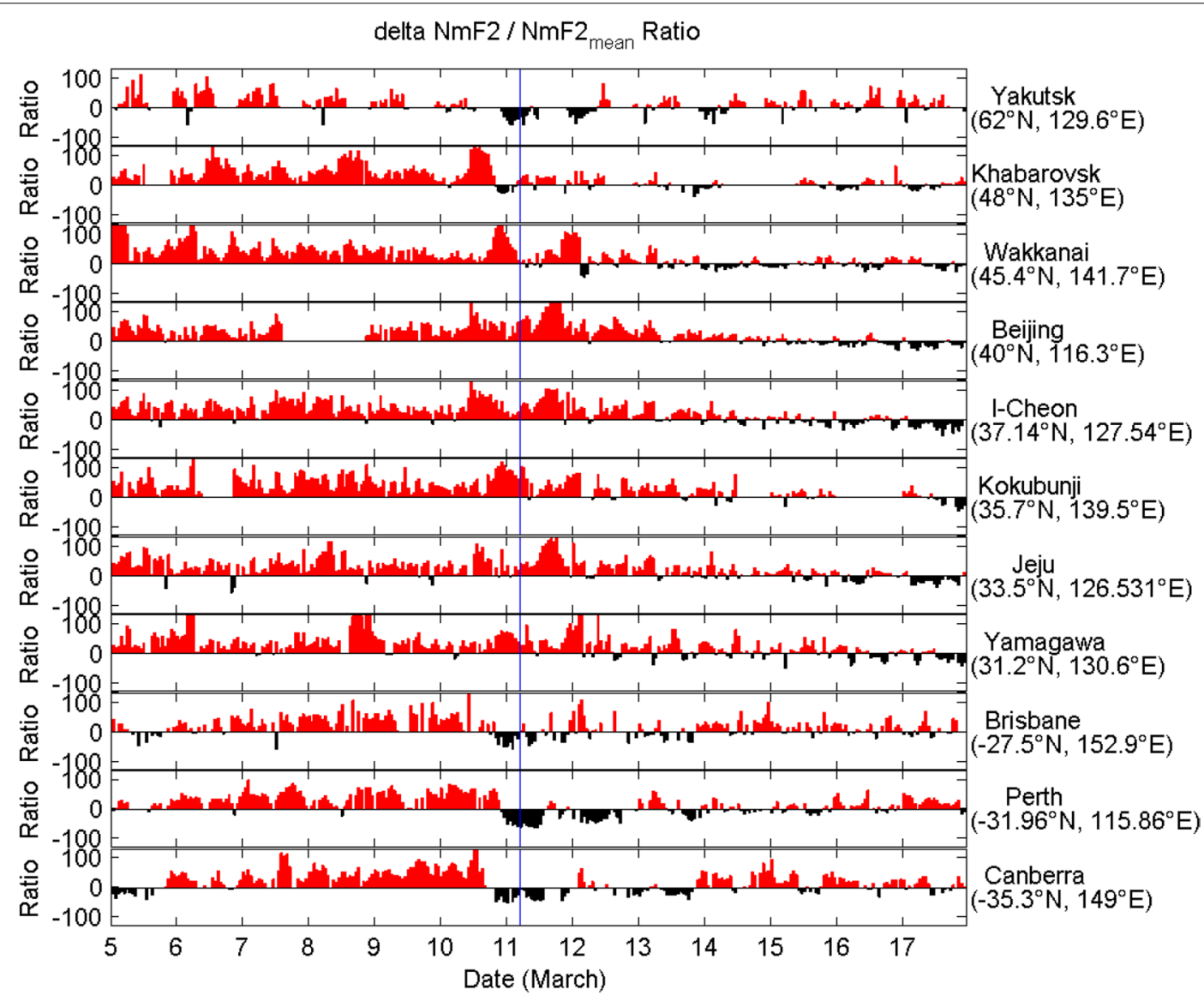

Fig. 3 Variation of NmF2 expressed by NmF2/NmF2 mean for 11 ionosonde stations located nearly at the same longitude of Japan. Red and black colors indicate the increase and decrease respectively. Blue thin vertical line indicates the time of EQ occurrence. Note the similar variation at Wakkanai, Beijin, I-Cheon, Kokubunji, and Jeju, NmF2/NmF2 mean at Yamagawa does not show any similarity to the four stations. $\mathrm{NmF2/NmF2} \mathrm{mean} \mathrm{at}$ Yakutsuku, Brisbane, Perth, and Canberra shows the negative value. These facts seem to suggest the ionopshere disturbancce related to EQ

that similar variation pattern is found on 10th and 11th at Wakkanai, Beijin, InCheon, Kokubunji, and Jeju. It is also noted (Fig. 4) that the increase of NmF2 is found during night time of March 8, 9, and 10. Especially, the increase on March 10 is the largest as marked by black arrow in Fig. 4 (Khabarosk). The increase of NmF2 starting from around $16 \mathrm{LT}$ to midnight is larger at higher latitude station and the increase becomes less as the observation latitude becomes lower such as Hokkaido and Kokubunji. The similar increase is identified on March 27 to April 1 which is possibly due to the EQ of $M=6.2$ which occurred on 27th March. These features might be explained by the enhanced eastward electric field during daytime, and enhanced westward electric field during night time as we discuss in detail in "Discussion" section.

\section{Satellite data for March 11, $2011 \mathrm{EQ}$}

The US satellite, DMSP, and Formosat-3/COSMIC were in orbit during the EQ. Although the height of the DMSP satellite seems to be too high to identify the epicenter location, data show several features which are possibly related to the EQ. Figure 5 shows the density of atomic oxygen ion $\mathrm{O}^{+}$along the DMSP orbit. In the figure, mid-latitude and main troughs in the southern hemisphere are marked by arrows. Although the trough structure in northern hemisphere is also identified, the trough structure in southern hemisphere is clearer than in northern hemisphere. Appearance of the troughs in both hemispheres suggests the role of electric field by two reasons:(1) evolution of mid -latitude trough, being detached from main trough, and (2) its equatorward movement with the approach of the EQ occurrence.

These two troughs are marked by black-blue (main trough) and by light blue (mid-latitude trough). Latitudinal change of the mid-latitude trough is larger than that of main trough. The shift to lower latitude becomes the largest during March 10 and 11. The latitudinal shift is steeper around the epicenter as EQ day approaches. Even considering the generally accepted equatorward shift with respect to the increasing magnetic disturbance, the 

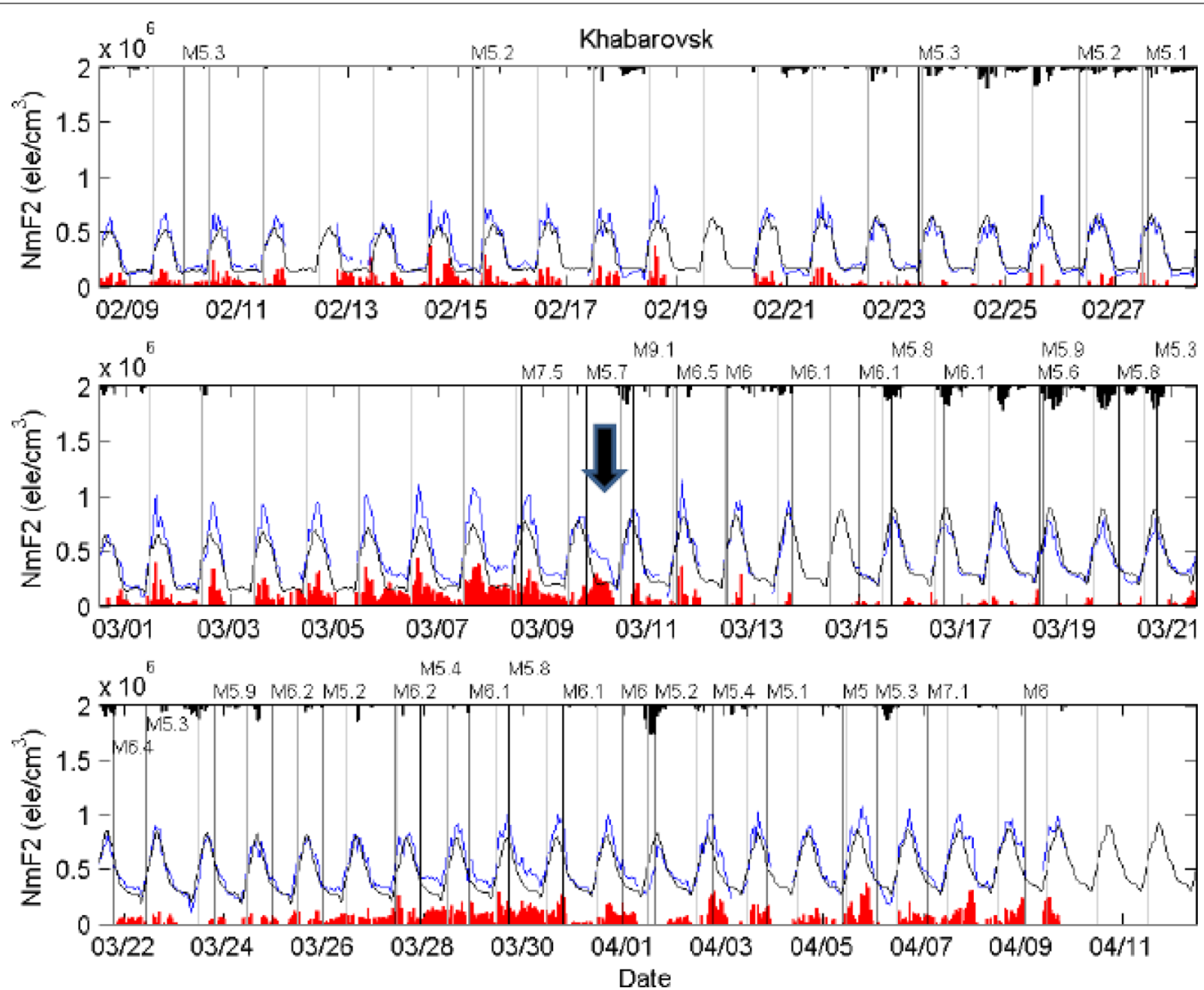

Fig. 4 NmF2 at Khabarovsk from February 9 to April 9, 2011. Black line indicates monthly average NmF2 centered on each day, and blue line indicates the daily NmF2. Vertical lines indicate the days of EQs. The largest night-time increase of NmF2 is marked by a black arrow

feature seems to be real. Information on $\mathrm{H}^{+}$as well as on the plasma temperature might be useful to understand these findings. Apart from earthquake-related study, mid-latitude trough itself needs further detailed study (Rodger et al. 1992; Yizengaw and Moldwin 2005).

\section{DEMETER data analysis}

Electron density Ne measured by DEMETER satellite is analyzed (Ryu et al. 2016). One example of the results is shown in Fig. 6 for EQ which occurred on March 25, $2007\left(37.13^{\circ} \mathrm{N}, 136.44^{\circ} \mathrm{E}\right)$ listed in Table 1. Following this EQ (marked as A in the figure), two other EQs (B and $C$ ) occurred. We define NEPD (Normalized Equatorial Plasma Density) as $\mathrm{Ne}_{\mathrm{eq}} / \mathrm{Ne}_{\text {mid }}$, as proposed by Ryu et al. (2014b). $\mathrm{Ne}_{\mathrm{eq}}$ is over geomagnetic equator, and $\mathrm{Ne}_{\text {mid }}$ is the average of $\mathrm{Ne}$ in mid-latitude of both hemispheres.

As the 2nd panel shows, NEPD shows $\mathrm{Ne}$ increase prior to EQ marked as A. The increase starts from 12 days before the EQ and return to baseline. Similar $\mathrm{Ne}$ increase is identified for other two EQs. Difference of the $\mathrm{Ne}$ increase between geomagnetic disturbance and earthquake disturbance is that for geomagnetic disturbance, Ne increases over the whole latitude, while for earthquake disturbance, the density increase is limited to equatorial region. This data analysis method might need to be added for earthquake prediction.

\section{Discussion}

The mechanism(s) of generating the ionosphere disturbances is most probably an electric field. However, generation mechanism of the electric field is not yet known.

Several mechanisms for the generation of the electric field and its effects on the ionosphere have been proposed. One is the stress-activated positive (or negative) hole (Freund et al. 2006). Freund et al. claim that a large electric field is generated as a result of this mechanism. Several computer simulations were conducted with this idea (Kuo et al. 2014). On the other hand, there is an argument that a current whose origin is in the ground might be too small to disturb the ionosphere (Pulinets and Ouzounov 2010).

Pulinets and Davidenko (2014) suggest that radon emanation produces cluster ions, and then cloud formation 


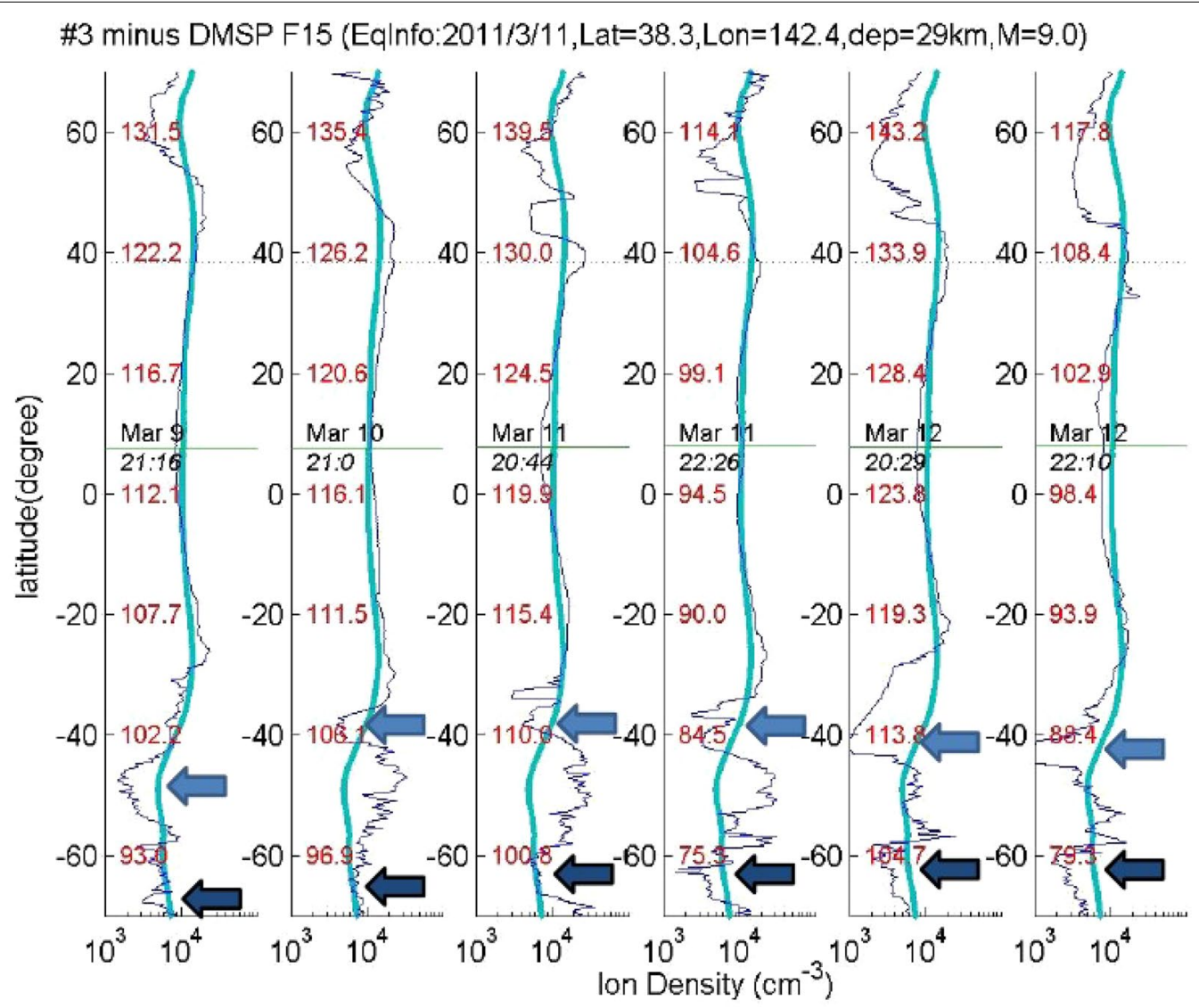

Fig. $5 \mathrm{O}^{+}$density variation along each DMSP orbit during 9-12 March. Vertical axis and horizontal axis indicate geographic latitude and atomic oxygen ion density, respectively. In each orbit, longitude of the satellite location is marked by red colored number. Thick light blue line indicates the atomic ion density averaged over $\pm 40^{\circ}$ from the epicenter longitude. Thin black-blue line indicates atomic oxygen ion density for each satellite orbit. Horizontal green line between 0 and $20^{\circ}$ in geographic latitude is geomagnetic equator, where day and UT are indicated by black letters. Thin dotted line which is close to $40^{\circ}$ in north indicates the EQ epicenter. Black-blue and light blue arrows in each orbit in the southern hemisphere indicate main and mid-latitude trough, respectively. Main trough in the northern hemisphere is not shown in the figure because the latitude of main trough is located at the latitude higher than $60^{\circ}$ in geographic latitude

occurs (Harrison et al. 2013), which finally produces latent heat. The cluster ions/aerosol size particles cause an air conductivity change and a humidity drop at a height close to the Earth's surface.

The ideas stated above suggest a charge of single polarity in the ionosphere. On the other hand, satellite data analysis suggests a different mechanism for the ionosphere disturbance. According to our analysis of electron temperature, $\mathrm{Te}$, obtained with a Japanese satellite HINOTORI (Oyama et al. 2008) and $\mathrm{O}^{+}$with the US satellite (DE-2) (Oyama et al. 2011), the ionosphere behavior seems to be the same both west and east of the epicenter. The distribution of positive (negative) charges (Freund et al. 2006) suggests a reduced (increased) electric field in the west and an enhanced (reduced) electric field in the east. This might produce the asymmetry of the plasma behavior in the EW direction.
The density of the atomic oxygen ion along the DE-2 satellite orbit suggests that the electric field should have the same direction in the entire disturbed area. This leads us to propose a different mechanism from those proposed by Freund et al. (2006) and Pulinets and Davidenko (2014). That is, the usual eastward electric field during day and westward electric field at night in the ionosphere are simply enhanced as Fig. 7 shows.

The idea seems to be partly supported by Thermosphere Ionosphere Mesosphere Electrodynamics/Broad Band Emission Radiometry (TIMED/SABER) data. For the Pingtung and Wenchuan EQs, which occurred on May 8, 2008 (Depth $=19 \mathrm{~km}, \mathrm{Mw}=7.9)$ and on December 26, 2006 (Depth $=44 \mathrm{~km}, \mathrm{M}=7.0$ ), respectively, $\mathrm{NmF2}$ increases on the same day that the amplitude of the atmospheric temperature ( $\mathrm{Tn})$ variation of the 20-30 km wavelength range in vertical scale increases 


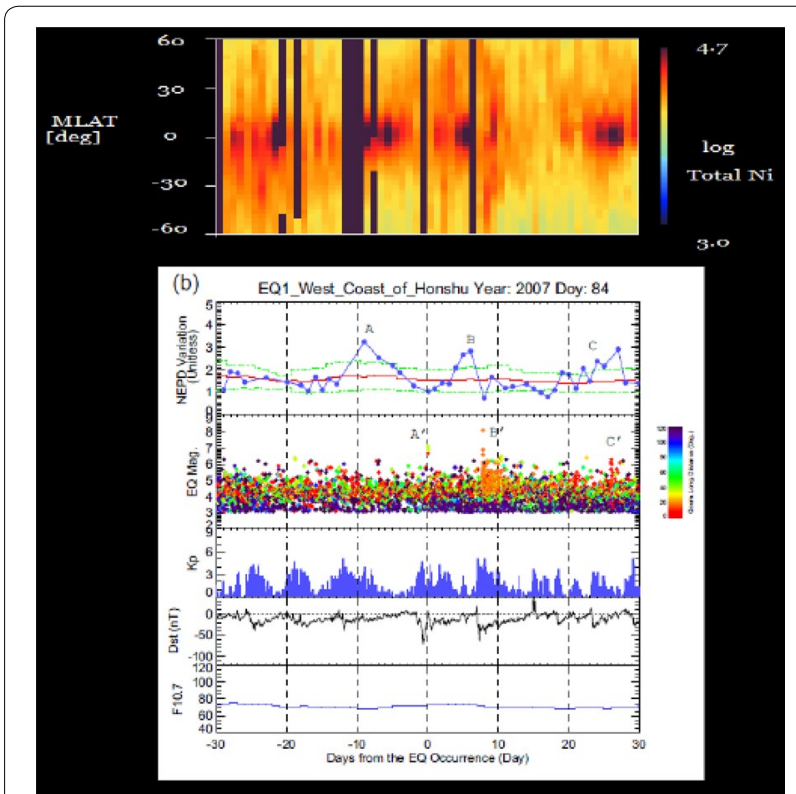

Fig. 6 Dialy variation of NEPD during 2 months for EQ which occurred on March 25, 2007 (marked as A in the 2nd panel). Two other EQs are marked as B and C. Top panel shows Ne over whole latitudes around Japan longitude. The second panel shows NEPD. The third panel shows the magnitude of the earthquake at the left, and distance from the epicenter in color code. Red color shows the closest. Three panels in the bottom show space weather information (Kp, Dst, and F10.7)

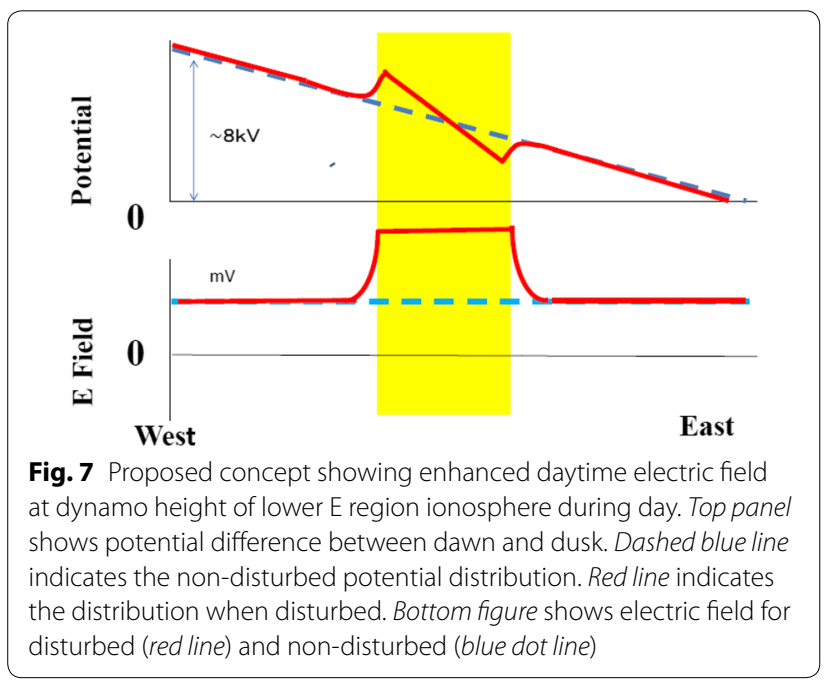

around the height of $100 \mathrm{~km}$ (Sun et al. 2011). Fluctuations of VLF waves received as signals of transmitted radio waves have also been reported (Rozhnoi et al. 2007). Muto et al. (2009) suggested the role of atmospheric gravity waves in the seismo-ionosphere perturbations as detected by sub-ionospheric VLF/LF propagation. These reports seem to suggest that atmospheric gravity waves
(AGWs) propagated from near the Earth's surface break around the dynamo region. As a result, the breaking of these AGWs might produce the locally enhanced eastward electric field during day and the westward electric field during night. The role of AGWs has been discussed by Klimenko et al. (2011), who attributed the NmF2 increase to a change in the neutral composition. Very recently, the ionospheric response to infrasonic acoustic waves generated by natural hazard events has been reported (Zettergren and Snively 2013). Their computer simulations seem to support the idea that no clear disturbance appears directly above the epicenter. We expect that further study will be conducted on the role of gravity waves in the dynamo region. However, note that ionosphere disturbances may be caused by more than one mechanism.

\section{Need for a satellite constellation}

To identify global features of EQ precursors, satellite constellation mission is essential for the reasons below (Oyama et al. 2010).

1. Ground-based observations, which are limited to a small geographic region such as Japan, are insufficient for a detailed assessment of the geographic extension of the affected area.

2. Number of large EQs $(M>7)$ which occur locally is small, which makes it difficult to identify common features. On average, one strong EQ $(M>7)$ occurs in Japan per year. Globally, about 10 strong EQs $(M>7)$ occur per year.

3. The accuracy of ionosonde and TEC data is insufficient to identify the epicenter, while satellite instruments can measure even small changes in plasma density. The disturbance due to the EQ might be too small to detect directly above the epicenter.

4. Continuous satellite data over the globe covering epicenters can provide a clear picture of the development of pre-EQ anomalous features.

5. Height of the satellite orbit should be around $300 \mathrm{~km}$, even partly, and should cover all local times. So far, only DE-2 satellite meets partly these requirements (Oyama et al. 2011).

The most essential reason for the requirement of a satellite constellation mission is that the observations from only one satellite are insufficient for the reasons described above. By targeting future satellite missions, we organized a small satellite payload task group under the Asia Oceania Geoscience Society (AOGS) in 2013 [http://www.geocities.jp/s2ptg]. Our idea is to ask for the provision of tiny satellites $(10-50 \mathrm{~kg})$, to countries that regularly experience EQ disasters especially Asian 
countries. The satellite should accommodate one common instrument to measure $\mathrm{Ne}$ and $\mathrm{Te}$ (Oyama et al. 2015a, b, c).

The current situation of satellite missions is described here. France took over the initiative and its small satellite DEMETER (Parrot et al. 2006) has already clarified through statistical analysis of $9000 \mathrm{EQs}$ that the nighttime attenuation of VLF range electromagnetic emission occurs $4 \mathrm{~h}$ before EQs larger than M4.8. However, the DEMETER was launched into a sun-synchronous orbit and its observations are limited to the fixed local time in day and night. The European Space Agency launched the Swarm satellite constellation to measure the Earth's magnetic field in 2013. Ne and Te measurements are not accurate due to the electrode contamination of DC Langmuir probe (Oyama et al. 2012). To investigate the preparatory phase of EQs, the Swarm for Earthquake Study (SAFE) project has been started in 2015 funded by the European Space Agency.

China is particularly eager and is planning to launch their first Seismo-Electromagnetic Satellite, Zhangheng-1, with the China Earthquake Administration and China National Space Administration in cooperation with the Italian Space Agency in 2016 (Wan et al. 2015). They plan to add two more satellites several years later. China also supports "Research on Determining Precursor Ionospheric Signatures of Earthquakes by Ground-based Ionospheric Sounding" and "Electromagnetic Satellite Payload for Earthquake Prediction" in the framework of the Asia-Pacific Space Cooperation Organization (APSCO).

\section{Concluding remarks}

To accelerate the study of using the ionosphere as EQ precursors and confirm their applicability for predicting future EQs, a microsatellite constellation mission is essential. For the realization of such a mission, we need to identify definite persuasive signature from large EQs, which will make it possible to form a working group for the satellite mission.

While we prepare for such a near future satellite mission, further analysis of the existing data acquired from available satellites such as DMSP, CHAMP, Formosat-3/ COSMIC, and Formosat-1 (ROCSAT-1) should be continued. We stress here that international collaboration can accelerate the process to get global morphology of ionosphere disturbance, as well as understand its physical mechanism.

\section{Authors' contributions}

KO worked on the DMSP and CHAMP data analysis and wrote most of the manuscript. He also established Small Satellite Payload Task Group on the AOGS since 2013. MD worked on event study by ionosonde data. KR worked on the DEMETER data analysis. CC worked on the Formosat-3/COSMIC TEC, height profile of Ne and GIM. JL worked on the TEC statistics. HL worked on the CHAMP data analysis. LB worked on DMSP and DEMETER ion data analysis. TK wrote the need for a satellite constellation, supervised the complete manuscript, and approved it for the final version to be published. All authors read and approved the final manuscript.

\section{Author details}

${ }^{1}$ International Center for Space Weather Study and Education, Kyushu University, Fukuoka, Japan. ${ }^{2}$ Institute of Plasma and Space Science, National Cheng Kung University, Tainan, Taiwan. ${ }^{3}$ Department of Physics, Gauhati University, Guwahati, Assam, India. ${ }^{4}$ Satellite Technology Research Center, Korea Advanced Institute of Science and Technology, Daejeon, Republic of Korea. ${ }^{5}$ Department of Earth Science, National Cheng Kung University, Tainan, Taiwan. ${ }^{6}$ Institute of Space Science, National Central University, Chung-Li, Taoyuan, Taiwan. ${ }^{7}$ Department of Earth and Planetary Sciences, Kyushu University, Fukuoka, Japan. ${ }^{8}$ Space Research and Technology Institute, Bulgarian Academy of Sciences, Sofia, Bulgaria. ${ }^{9}$ Japan Aerospace Exploration Agency, Tsukuba, Japan.

\section{Acknowledgements}

We express our deep acknowledgement to the Mitsubishi Foundation for providing research fund (ID: 26113). Our international collaboration was not possible without the support. We also express our sincere thanks to Dr. Hui-Kuan Fang, of National Cheng Kung University, Taiwan, and Dr. T. Uozumi, International Center for Space Weather Study and Education, Kyushu University, Japan, for their help. We are thankful to all related agencies for providing us satellite (DMSP, DEMETER, CHAMP, and Formosat-3/COSMIC) and groundbased data (NmF2 and TEC). Our final acknowledgement goes to reviewer of the manuscript for careful reading and for giving important comments, especially for suggesting the better terms and sentences.

\section{Competing interests}

The authors declare that they have no competing interests.

Received: 2 December 2015 Accepted: 10 February 2016

Published online: 01 March 2016

\section{References}

Astafyeva E, Heki K (2011) Vertical TEC over seismically active region during low solar activity. J Atmos Solar Ter Phys 73:1643-1652

Akhoondzadeh M, Parrot M, Saradjian MR (2010) Electron and ion density variations before strong earthquakes(M 6.0) using DEMETER and GPS data. Nat Hazards Earth Syst Sci 10:7-18

Aleksandrin SY, Galper AM, Grishantzeva LA, Koldashov SV, Maslennikov LV, Murashov AM, Picozza P, Sgrigna V, Voronov SA (2003) High energy particle bursts in the near-earth space as earthquake precursors. Annales Geophys 21:597-602

Devi M, Barbara AK, Depueva A, Ruzhin YY, Depueva V (2010a) Anomalous total electron content (TEC) and atmospheric refractivity prior to the very strong China earthquake of May 2008. Int J Remote Sens 31(13):3589-3599

Devi M, Barbara AK, Kashyap P, Sepueva A, Ruzhin YY, Depueva V (2010b) Earthquake time low latitude TEC and model estimated values: identification on earthquake induced atmospheric dynamics. Adv Geosci 26:69-83

Devi M, Medhi A, Sarma AJD, Barbara AK (2013) Growth and Inhibition of equatorial anomaly prior to an earthquake (EQ): case studies with total electron content (TEC) data for major EQs of Japan 2011 and Indonesia 2012. Positioning 4:240-252

Depueva A, Rotanava NM (2000) Modification of low-latitude and equatorial ionosphere before large earthquakes. Geomagn Aero 40(6):50-54

Dobrovolsky IP, Zubkov SI, Miyachkin VI (1979) Estimation of the size of earthquake preparation zones. Pure Appl Geophys 117:1025-1044. doi: 1007/ BF00876083

Freund TF, Takeuchi A, Lau WS (2006) Electric currents streaming out of stressed igneous rocks - a step towards understanding pre-earthquake low frequency EM emissions. Phys Chem Earth 31:389-396

Harrison RG, Aplin KL, Rycroft MJ (2013) Earthquake-cloud coupling through the global atmospheric electric circuit. Nat Hazards Earth Syst Sci 1:7271-7283

Hayakawa M, Kasahara Y, Nakamura T, Muto F, Horie T, Maekawa S, Hobara Y, Rozhnoi AA, Solovieva M, Molchanov OA (2010) A statistical study on 
the correlation between lower ionospheric perturbations as seen by subionospheric VLF/LF propagation and earthquakes. J Geophys Res 115:A09305

Jhuang HK, Ho YY, Kakinami Y, Liu JY, Oyama K-I, Parrot M, Hattori K, Nishihashi M, Zhang D (2010) Seismo-ionospheric anomalies observed by GPS-TEC before the 12 May 2008 M7.9 Wenchuan earthquake. Inter J Remote Sensing 31(13):3579-3587T

Klimenko MV, Klimenko WV, Karpov IV, Zakharenkova IE (2011) Simulation of Seismo-lonospheric effects initiated by internal gravity wave. Russian J Phys Chem B 5:393-401

Kuo CL, Lee LC, Huba JD (2014) An improved coupling model for the lithosphere-atmosphere-ionosphere system. J Geophys Res 119:3189-3205

Liu JY, Chen YI, Jhuang HK, Lin YH (2004) lonospheric foF2 and TEC anomalous days associated with $M>5.0$ earthquakes in taiwan during 1997-1999. Terr Atmos Oceanic Sci 15:371-383

Liu JY, Chen CH, Tsai HF (2014a) A statistical study on ionospheric precursors of the total electron content associated with $146 \mathrm{M}>6.0$ earthquakes in Japan during 1998-2011. In: Hayakawa M (ed) Earthquake prediction studies: seismo electromagnetics. Terrapub, Tokyo, pp 1-13

Liu J, Huang J, Zhang X (2014b) lonospheric perturbations in plasma parameters before global strong earthquakes. Adv Sp Res 53:776-787

Muto F, Kasahara Y, Hobara Y, Hayakawa M, Rozhnoi A, Solovieva M, Molchanov OA (2009) Further study on the role of atmospheric gravity waves on the seismo-ionospheric perturbations as detected by subionospheric VLF/LF propagation. Nat Hazards Earth Sys Sci 9:1111-1118

Ouzounov D, Freund F (2004) Mid-infrared emission prior to strong earthquakes analyzed by remote sensing data. Adv Space Res 33:268-273

Oyama K-I, Kakinami Y, Liu JY, Kamogawa M, Kodama T (2008) Reduction of electron temperature in low-latitude ionosphere at $600 \mathrm{~km}$ before and after large earthquakes. J Geophys Res 113:A11317

Oyama K-I, Kakinami Y, Liu JY, Kodama T, Chen CY (2010) Micro/mini satellites for earthquake studies - toward international collaboration. Adv Geosci 21:251-256

Oyama K-I, Kakinami Y, Liu JY, Abdu MA, Cheng CZ (2011) Anomalous ion density latitudinal distribution as a precursor of large earthquake. J Geophys Res 116:A04319

Oyama K-I, Lee CH, Fang HK, Cheng CZ (2012) Means to remove electrode contamination effect of Langmuir probe measurement in space. Rev Sci Instrum 83:055113. doi:10.1063/1.4722167

Oyama K-I, Ryu K, Chen CH, Minakshi D, Liu H, Liu JY (2015a) Diversity of ionosphere modification possibly caused by large earthquakes (ST09-A006), presented at AOGS, Aug.6 2015

Oyama K-I, Fang HK, Yakinami Y, Ryu K, Chen CH, Liu H, Minakshi D, Liu JY (2015b) Study on ionosphere precursor and International Reference Ionosphere, presented at IRI workshop, Thailand 9-12, 2015

Oyama K-I, Hsu YW, Jiang GS, Chen WH, Fang HK, Cheng CZ, Liu WT (2015b) Electron temperature and density probe for small aeronomy satellites. Rev Sci Instr 86:084703. doi:10.1063/1.4927342

Parrot M, Berthelier JJ, Lebreton JP, Sauvaud JA, Santolik O, Blecki J (2006) Examples of unusual ionospheric observations made by the DEMETER satellite over seismic regions. Phys Chem Earth 31:486-495

Pulinets S, Davidenko D (2014) Ionospheric precursors of earthquakes and Global circuit. Adv Space Res 54:709-723

Pulinets S, Ouzounov D (2010) Lithosphere-Atmosphere- ionosphere coupling (LAIC) model-an unified concept for earthquake precursors validation. J Asian Earth Sci 41(4-5):371-382

Rishbeth H (2007) Do earthquake precursors really exist? Eos 88(29):296

Rodger AS, Mofett RJ, Quegan S (1992) The role of ion drift in the formation of ionization troughs in the mid-and high latitude ionosphere-a review. J Atmos Terr Phys 54:1-30

Rozhnoi A, Solovieva M, Molchanov O, Biagi PF, Hayakawa M (2007) Observation evidences of atmospheric gravity waves induced by seismic activity from analysis of subionospheric LF signal spectra, 2007. Nat. Hazard Earth Sci. 7:625-628
Ryu K, Lee E, Parrot M, Oyama K-I (2014a) Multisatellite observations of enhancement of equatorial ionization anomaly around Northern Sumatra earthquake of March 2005. J Geophys Res 119:4767-4785

Ryu K, Lee E, Chae JS, Parrot M, Pulinets S (2014b) Seismo-ionospheric coupling appearing as equatorial electron density enhancements observed via DEMETER electron density measurements. J Geophys Res Sp Phys 119:8524-8542

Ryu K, Parrot M, Kim SG, Jeong KS, Chae JS, Pulinets S, Oyama K-I (2014C) Suspected seismo-ionospheric coupling observed by satellite measurements and GPS TEC related to the M7.9 Wenchuan earthquake of 12 May 2008. J Geophys Res Sp Phys 119:10305-10323

Ryu K, Oyama K-I, Bankov L, Minakshi D, Koichi CH, Liu JY, Liu H (2016) Precursory equatorial ionospheric density enhancement: contribution from Mid-latitude large earthquakes in the North-East Asian region. Adv Space Res 57:268-280

Saradjian MR, Akhoondzadeh M (2011) Prediction of the date, magnitude and affected area impending strong earthquakes using integration of multiprecursors earthquake parameters. Nat Hazards Earth Syst Sci 11:1109-1119

Sgrigna V, Carota L, Conti L, Corsi M, Galper AM, Koldashov SV, Murashov AM, Picozza P, Scrimaglio R, Stagni L (2006) Correlations between earthquakes and anomalous particle bursts from SAMPEX/PET satellite observations. J Atmos Solar Terr Phys 67:1448-1462

Sun YY, Oyama K-I, Liu JY, Jhuang HK, Cheng CZ (2011) The Neutral Temperature in the lonospheric Dynamo Region and the Relation with the Ionospheric Density during Wenchuan and Pingtung Earthquakes. Nat Hazard Earth Syst Sci 11:1759-1768

Wan LW, Shen XH, Zhang Y, Yan R (2015) Preliminary proposal of scientific data verification in CSES mission. Earthquake Sci 28:303-310

Yigen E, Moldwin M (2005) The altitude extension of the mid-latitude trough and its correlation with plasma pause position. Geophys Res Lett 32:L09105

Zakharenkova IE, Shagimuratov II, Krankowski A, Lagovsky AF (2007) Precursor phenomena observation in the electron content measurements before great Hokkaido earthquake of September 25, 2003, ( $M=8.3)$. Stud Geophys Geod 51:267-278

Zhao B, Wang M, Yu T, Wan W, Lei J, Liu L, Ning B (2008) Is an unusual large enhancement of ionospheric electron density linked with the 2008 great Wenchuan earthquake? J Geophys Res 113:A11304

Zettergren MD, Snively JB (2013) lonospheric response to infrasonic_-acoustic waves generated by natural hazard events. J Geophys Res 40:5345-5349

\section{Further Reading}

Earthquake Prediction with Radio Techniques, Hayakawa (2015) John Wiley and Sons, Singapore Pte Ltd. http://onlinelibrary.wiley.com/ book/10.1002/9781118770368

Valery Sorokin, Vitaly Chmyrev, Masashi Hayakawa (2014) Electrodynamic coupling of lithosphere-atmosphere-ionosphere of the Earth. Nova Science Publishers https://www.novapublishers.com/catalog/product_info. php?products_id $=55228$

Earthquake prediction studies: seismo electromagnetics. In: Masashi Hayakawa, ed, Terra Scientific Publishing Company http://www.terrapub. co.jp/books/index.html

The frontier of earthquake prediction studies (2012) In: Masashi Hayakawa, ed Nihon Senmontosho Shuppan http://www.jpn-shuppan.co.jp/books/ book8.html

Sergey Pulinets, Kyrill Boyarchuk (2004) Ionospheric Precursors of Earthquakes. Springer http://www.springer.com/us/book/9783540208396

Ikeya M (2004) Earthquakes and Animals: "From folk legend to Science,"World Scientific

Rikitake T (2003) Predictions and precursors of major earthquakes, Terra scientific publishing company, Tokyo, ISBN 4-88704-128-4 